\title{
Correction to: Do Bisphosphonates Alleviate Pain in Children? A Systematic Review
}

\author{
Mercedes Rodriguez Celin ${ }^{1}$ (D) - Jacqueline C. Simon ${ }^{1,2} \cdot$ Joseph J. Krzak ${ }^{1,3} \cdot$ Alissa V. Fial $^{4} \cdot$ Karen M. Kruger $^{1,2}$. \\ Peter A. Smith ${ }^{1}$. Gerald F. Harris ${ }^{1,2}$ \\ Published online: 29 October 2020 \\ (C) Springer Science+Business Media, LLC, part of Springer Nature 2020
}

\section{Correction to: Current Osteoporosis Reports (2020) 18:486-504 https://doi.org/10.1007/s11914-020-00621-3}

In a previous version of this publication, the author Mercedes Rodriguez Celin's name was listed as M.R. Celin. The correct appearance of her name is M. Rodriguez Celin.

In a previous version, the author Jacqueline Simon appears as Jackeline, an incorrect spelling.

Publisher's Note Springer Nature remains neutral with regard to jurisdictional claims in published maps and institutional affiliations.

The online version of the original article can be found at https://doi.org/ $10.1007 / \mathrm{s} 11914-020-00621-3$

Mercedes Rodriguez Celin

mercedesrodriguezcelin@gmail.com

1 Motion Analysis Center, Shriners Hospitals for Children, Chicago, IL, USA

2 Orthopaedic and Rehabilitation Engineering Center, Marquette University, Milwaukee, WI, USA

3 Physical Therapy Program, College of Health Sciences, Midwestern University, Downers Grove, IL, USA

4 Research and Instructional Services, Raynor Memorial Libraries, Marquette University, Milwaukee, WI, USA 